Fanum

Sociológico
Forum Sociológico

Série II

$23 \mid 2013$

Número 23

\title{
Estado social e alimentação escolar: criatividade na austeridade
}

Mónica Truninger, José Teixeira, Ana Horta, Sílvia Alexandre e Vanda A. da Silva

\section{(2) OpenEdition}

\section{Journals}

\section{Edição electrónica}

URL: https://journals.openedition.org/sociologico/723

DOI: 10.4000/sociologico.723

ISSN: 2182-7427

Editora

CICS.NOVA - Centro Interdisciplinar de Ciências Sociais da Universidade Nova de Lisboa

Edição impressa

Data de publição: 1 novembro 2013

Paginação: 11-19

ISSN: 0872-8380

\section{Refêrencia eletrónica}

Mónica Truninger, José Teixeira, Ana Horta, Sílvia Alexandre e Vanda A. da Silva, «Estado social e alimentação escolar: criatividade na austeridade», Forum Sociológico [Online], 23 | 2013, posto online no dia 01 janeiro 2014, consultado o 29 março 2022. URL: http://journals.openedition.org/sociologico/ 723 ; DOI: https://doi.org/10.4000/sociologico.723

Este documento foi criado de forma automática no dia 29 março 2022.

(c) CICS.NOVA 


\section{Estado social e alimentação escolar: criatividade na austeridade}

Mónica Truninger, José Teixeira, Ana Horta, Sílvia Alexandre e Vanda A. da Silva

\section{Introdução}

1 Em Portugal, a escola desempenha um papel importante no acesso ao consumo de refeições nutricionalmente equilibradas, sobretudo junto de crianças e jovens que se encontram em situação de insegurança alimentar. Muitas vezes, o almoço na escola constitui a única refeição quente do dia de crianças e jovens de famílias carenciadas. A refeição na escola pública encontra-se juridicamente enquadrada por critérios de qualidade, nutrição, segurança e higiene. $O$ serviço escolar de refeições visa contribuir quer para a segurança alimentar da população juvenil, quer para a adequação dos seus hábitos alimentares a critérios regidos por visões particulares sobre a saúde, propostos pela medicina e pelas ciências da nutrição (Evans, 2010). Porém, este sistema de provisão, sustentado no Estado Social, encontra-se fragilizado na sequência da crise financeira espoletada em 2008 e, mais concretamente, das atuais políticas de austeridade em curso no país. Questões como o aumento do IVA nas refeições escolares, dívidas dos municípios aos fornecedores de alimentos, cortes na despesa e estrutura orgânica do Estado e restrições às transferências financeiras para os municípios ameaçam a eficácia e abrangência deste sistema de provisão das refeições escolares.

2 No entanto, se, por um lado, a crise tem vindo a colocar desafios às famílias portuguesas mais carenciadas no acesso ao consumo alimentar em geral, por outro lado, parece estar também a conduzir a rearranjos institucionais criativos nos modos de provisão alimentar, nomeadamente na escola. Veja-se, por exemplo, a extensão da abertura dos refeitórios escolares para além do período letivo, nomeadamente nas férias (e.g. Carnaval, Páscoa), de forma a facultar uma refeição às crianças de famílias em dificuldade económica. Episódios como este, em que se evidencia o papel determinante de certos agentes sociais no colmatar de situações de escassez e insegurança 
alimentares, revelam elementos de uma cidadania ativa, veiculada através da capacidade relativamente autónoma e criativa das autoridades locais e dos agrupamentos de escolas. Estas iniciativas criativas merecem uma análise mais aprofundada de forma a perceber que papéis têm na reconfiguração do Estado Social, nomeadamente no que toca à manutenção regular de bens e serviços para o bem-estar das populações. Neste artigo procura-se, por um lado, compreender alguns "arranjos criativos"1 na flexibilização institucional da gestão dos apoios sociais em algumas escolas selecionadas das regiões de Lisboa, Norte e Madeira. Por outro lado, procura-se perceber em que medida algumas iniciativas centralizadas do Estado estão a surgir de forma a colmatar os problemas decorrentes dos efeitos da crise económica e de políticas de teor mais neoliberal (privatização de serviços, transferência das competências do Estado Social para o setor privado, entre outras).

Deste modo, na primeira parte faz-se uma contextualização dos impactos da austeridade económica na sociedade portuguesa, focando com maior detalhe as condições de vida das famílias e os seus efeitos no consumo alimentar. Depois, tendo por pano de fundo o contexto de crise económica e as suas consequências nas famílias, identificam-se algumas das principais premissas teóricas que abordam a crescente fragilização do Estado Social, e a transferência de alguns serviços de proteção social para o mercado e a sociedade civil. Segue-se a apresentação dos procedimentos metodológicos necessários à recolha do material empírico em oito escolas das regiões de Lisboa, Norte e Madeira. Com base neste material, ilustram-se alguns dos arranjos institucionais criativos desenvolvidos pelas autarquias, pela comunidade escolar e por parcerias promovidas pelo próprio Estado de forma a colmatar problemas de alimentação escolar que se acentuaram com as políticas de austeridade, as quais têm provocado a retração do Estado Social. Por fim, retomam-se alguns dos argumentos teóricos expostos na primeira parte sobre o Estado Social e a sua reconfiguração, à luz das ilustrações empíricas identificadas. Estas mostram que o Estado - com todos os constrangimentos económicos que dificultam e limitam a sua ação - parece procurar desenvolver soluções institucionais criativas que, autonomamente ou em parceria com o mercado e a sociedade civil, permitem garantir a segurança alimentar das crianças nas escolas.

\section{Efeitos da austeridade económica no consumo alimentar das famílias com crianças}

4 Atualmente, na Europa, o contexto de crise económica e financeira tem conduzido a alguns desenvolvimentos políticos que põem em causa as condições de vida das populações, especialmente das que se encontram em situação de maior vulnerabilidade económica. Alguns países, pressionados pelos seus elevados níveis de dívida externa e respetivos credores, têm vindo a implementar um conjunto de políticas de austeridade que comprometem a efetividade do Estado Social no suprimento das necessidades de certos grupos populacionais mais vulneráveis e dos direitos fundamentais dos cidadãos, nomeadamente à alimentação e à saúde.

5 De acordo com um relatório publicado pela União Europeia (Comissão Europeia, 2012), em Portugal a imposição da austeridade levou a que os grupos com baixo capital económico tenham tido uma maior redução no rendimento disponível do agregado por comparação aos que detêm maior poder económico. Assiste-se, assim, ao aumento do 
desemprego, ao aumento da pobreza e à emergência de uma nova categoria - os "novos pobres" -, bem como ao surgimento de casos de dependência económica num contexto em que $14,7 \%$ das crianças e jovens até aos 17 anos vivem em condições de pobreza relativa e $27,4 \%$ experimentam situações de privação de bens essenciais ao seu desenvolvimento (UNICEF, 2012).

6 No que concerne às questões do consumo alimentar, apesar de as dinâmicas de modernização ocorridas em Portugal nas últimas décadas terem conduzido ao surgimento de uma "sociedade de consumo" (Santos, 2012; Cruz, 2011) e a uma redução das desigualdades de rendimentos (Costa, 2012), prevalece na sociedade portuguesa um conjunto de assimetrias e desigualdades no acesso à alimentação que têm vindo a ser agravadas no contexto da atual crise. Estas desigualdades refletem-se nos elevados níveis de comparticipação da alimentação escolar por parte da Ação Social. O fornecimento de refeições gratuitas (ou a preços comparticipados) continua a representar um instrumento governamental importante para atenuar os efeitos da carência alimentar (Truninger et al., 2012). Portanto, com a crise económica, assiste-se ao agravamento de um conjunto de indicadores estruturais de bem-estar, onde a alimentação escolar se inclui, a que se junta um processo de redução e/ou restruturação dos serviços públicos e da sua orgânica. Este cenário tem vindo a ser caraterizado como uma retração do Estado Social, um aspeto que se explora em mais detalhe no próximo ponto.

\section{Estado Social e alimentação escolar}

7 Em Portugal, o direito à alimentação nas escolas permitiu, desde os anos 70, que se reduzisse significativamente os níveis de insegurança alimentar nos grupos populacionais mais carenciados e que se melhorasse, de forma generalizada, os níveis de saúde e de escolarização da população escolar (Truninger et al., 2012). Apesar de existirem poucas referências na literatura académica nacional e internacional sobre o impacto da atual conjuntura de austeridade económica na provisão alimentar escolar (ver Morgan, 2011, para um dos poucos exemplos), há contributos teóricos e conceituais mais gerais que permitem refletir sobre a insegurança alimentar e a acentuação atual do distanciamento do Estado na proteção dos direitos dos cidadãos. Um dos argumentos centrais sobre a retração do Estado Social advoga que nos regimes democráticos e socialmente inclusivos os direitos dos cidadãos (como por exemplo o direito à alimentação e à saúde) assentam num equilíbrio frágil do triângulo de relações entre Estado, Mercado e Sociedade Civil. De acordo com Sulkunen (2009), o fundamento do Estado Social baseia-se na sua capacidade de promover segurança social por via da desmercantilização de um conjunto de bens e serviços, ou seja, de gerar bem-estar de uma forma generalizada por recurso a mecanismos redistributivos. Face à crise europeia das dívidas soberanas e às políticas de austeridade, os direitos de facto dos cidadãos estão cada vez mais comprometidos pela necessidade de conter a despesa pública. Perante esta condição, a gestão dos riscos e dos custos associados às políticas neoliberais transitam das instituições públicas que promovem a segurança social para os indivíduos e as famílias (Somers, 2008:2). Ao contrário da visão que define a sociedade civil como um espaço relativamente independente de negociação das lógicas de atuação do mercado sobre o Estado, a contratualização dos serviços públicos e a transferência de responsabilidades para os indivíduos e as famílias requer uma 
reorganização do papel da sociedade civil na redução dos custos do que Somers (2008:247) denomina por "fundamentalismo de mercado". Segundo esta autora, o fundamentalismo de mercado refere-se à organização da vida social e da esfera pública exclusivamente assente em mecanismos de mercado. Com esta transferência de responsabilidades do Estado para os cidadãos, o bem-estar associado aos sentimentos de segurança social passa a depender cada vez mais da autonomia dos indivíduos (Sulkunen, 2009) e, em particular, do valor do seu capital social (e.g. sacrifício pessoal, voluntariado, controlo social, partilha recíproca de informação, solidariedade) (Somers, 2008).

8 Em situações de "emergência social", o acesso ao consumo de bens e serviços fica comprometido pela degradação das funções sociais do Estado. Simultaneamente, observa-se uma crescente responsabilização moral da sociedade civil no suprimento das necessidades dos cidadãos (Dowler e O'Connor, 2012), em detrimento das estruturas de governança estrategicamente planificadas (Sulkunen, 2009). Por conseguinte, emergem parcerias e iniciativas criativas (ou "arranjos") dentro das redes de provisão do Estado (e.g. na rede de cantinas escolares) e das redes de provisão comunitárias (e.g. movimentos sociais contra a insegurança alimentar, bancos alimentares e outras organizações religiosas) (Lambie, 2011; Lambie-Mumford e Jarvis, 2012). A responsabilidade de garantir níveis adequados de segurança alimentar recai, sobretudo, na capacidade de os agentes sociais serem criativos e autónomos, isto é, capazes de desenvolver soluções (mesmo que provisórias e abertas).

Em muitas sociedades contemporâneas, a segurança alimentar depende em grande parte do poder aquisitivo dos cidadãos em contextos de mercado (Dowler e O'Connor, 2012). Apesar da forte hegemonia do mercado como facilitador do acesso ao consumo alimentar, a aquisição, apropriação e uso de bens e serviços não depende somente de relações de troca comerciais. Harvey et al. (2001: 62), depois de Warde (1992), sugerem uma tipologia de organização das redes de provisão de bens e serviços que vai para além das relações de mercado (Quadro 1).

Quadro 1 [5] [9] Redes de provisão de bens e serviços

\begin{tabular}{|c|c|c|c|c|}
\hline $\begin{array}{c}\text { Redes de } \\
\text { Provisão }\end{array}$ & $\begin{array}{c}\text { Maneira através } \\
\text { da qual o serviço é } \\
\text { obtido }\end{array}$ & $\begin{array}{c}\text { Quem faz o } \\
\text { trabalho }\end{array}$ & $\begin{array}{c}\text { Princípio sob o } \\
\text { qual } \\
\text { a troca é } \\
\text { organizada }\end{array}$ \\
\hline Mercado & $\begin{array}{c}\text { Compra } \\
\text { comercial }\end{array}$ & $\begin{array}{c}\text { Trabalhadores } \\
\text { remunerados }\end{array}$ & Consumidor & $\begin{array}{c}\text { Troca de } \\
\text { mercado }\end{array}$ \\
\hline Estado & $\begin{array}{c}\text { Reivindicar um } \\
\text { direito }\end{array}$ & $\begin{array}{c}\text { Trabalhadores } \\
\text { remunerados }\end{array}$ & Estado & $\begin{array}{c}\text { Direitos de } \\
\text { cidadania }\end{array}$ \\
\hline Comunitária & $\begin{array}{c}\text { Relações } \\
\text { pessoais }\end{array}$ & $\begin{array}{c}\text { Vizinhos e } \\
\text { conhecidos }\end{array}$ & $\begin{array}{c}\text { Não há dinheiro } \\
\text { envolvido }\end{array}$ & $\begin{array}{c}\text { Obrigação } \\
\text { recíproca }\end{array}$ \\
\hline Doméstica você & $\begin{array}{c}\text { Faça vesmo } \\
\text { (espaço } \\
\text { doméstico) }\end{array}$ & $\begin{array}{c}\text { Membros da } \\
\text { familia }\end{array}$ & $\begin{array}{c}\text { Não há dinheiro } \\
\text { envolvido }\end{array}$ & Obrigações \\
\hline
\end{tabular}

Fonte: HARVEY ET AL., 2001, P. 62 (TRADUÇÃo PRóPRIA).

Esta tipologia tem a vantagem de não considerar o consumo como estando no final de uma longa cadeia de produção e distribuição de bens e serviços, mas sim como fazendo parte constituinte dos processos de produção e provisão alimentares. As relações de 
consumo e produção têm assim diferentes configurações, sendo as relações de mercado apenas uma das redes.

Nas redes de provisão estatais, os indivíduos têm acesso ao consumo ao reclamarem ou usufruírem de um direito social; os custos são suportados pelo Estado e o princípio sob o qual os bens e os serviços são obtidos é o dos direitos dos cidadãos (Harvey et al., 2001: 62). Em Portugal, os primeiros passos para a universalização do acesso à alimentação escolar aconteceram no início da década de 70. Mais tarde, a partir da década de 90, a maioria destes serviços passou a ser contratualizada com empresas de catering. Esta é uma forma de transferir para o mercado as despesas com as refeições e com os recursos humanos necessários para fazer chegar almoços e lanches aos alunos. Não obstante, as crianças têm acesso a refeições comparticipadas e subsidiadas de acordo com o escalão de ação social escolar em que se inserem (Truninger et al., 2012). Em alguns casos, além da refeição e do leite escolar ( ${ }^{\circ}$. ciclo) também é distribuído gratuitamente um lanche (ou suplemento alimentar) e por vezes fruta.

Nas redes de provisão comunitárias, os bens e serviços são alvo de trocas recíprocas e gratuitas com base em relações interpessoais. Aqui estão incluídas as trocas que resultam de doações provenientes da comunidade e que derivam da solidariedade ou da caridade dos seus elementos. Numa altura de crise económica há várias organizações e iniciativas que têm vindo a desempenhar o papel de "almofada" social, tentando acudir as famílias mais carenciadas (e.g. banco alimentar, associações de redistribuição dos desperdícios alimentares, igreja).

Além das redes de provisão do mercado, do Estado e comunitárias, Harvey et al. (2001) referem-se às domésticas. Estas remetem para um espaço onde os indivíduos preparam e recebem os alimentos gratuitamente de acordo com as obrigações familiares (Harvey et al., 2001: 62). As refeições em família continuam a ser um elemento central da vida pessoal e familiar, mesmo que sendo difíceis de implementar de forma sistemática na prática quotidiana (DeVault, 1991). Apesar de a refeição em família ser mais um ideal do que uma prática sistemática, uma parte significativa da alimentação é ainda feita através da rede familiar, a qual não envolve trocas de dinheiro entre os elementos do agregado.

Esta tipologia organizadora das redes de provisão de bens e serviços expressa tipos ideais e, como tal, a sua operacionalização empírica deve deixar margem para as relações fluidas entre estes diversos tipos. Essa fluidez pode expressar situações de confluência entre duas ou mais redes de provisão, tal como acontece quando se consolida uma parceria entre o Estado, a comunidade e a família, por exemplo. Esta tipologia parece ser pertinente para sistematizar um conjunto de arranjos institucionais criativos para solucionar algumas situações de insegurança alimentar das crianças nas escolas, que partem não só das redes de provisão estatal como também de parcerias entre o Estado, a comunidade, o mercado e a família.

\section{Procedimentos metodológicos}

15 Integrado num projeto de investigação mais amplo sobre o sistema de refeições escolares em Portugal ${ }^{2}$, este artigo recorre a uma pluralidade de fontes de informação empírica para tentar identificar e analisar os arranjos institucionais criativos presentes no sistema alimentar escolar. Tendo como objetivo analisar a organização deste sistema e os hábitos alimentares de crianças e famílias em contextos sociodemográficos 
diferenciados, foram selecionadas oito escolas do Ensino Básico público (1.ำ 2.ำ e 3.ำ ciclos) situadas em zonas das regióes de Lisboa, Norte e Madeira, com perfis contrastantes que obedeceram aos seguintes critérios de escolha: recorte urbano/ suburbano; proximidade de bairros sociais com população multicultural; proximidade de áreas cujas famílias são caracterizadas por deterem elevados níveis de capitais económico, cultural e social; inserção em programas de promoção da saúde escolar; diferentes tipos de contratualização das suas refeições (confeção local e com cozinha própria; ou com o serviço de refeições subcontratado a uma empresa de catering). 0 material empírico foi recolhido entre Novembro de 2011 e Abril de 2013, o qual consistiu em entrevistas com os professores e pessoal de cozinha das oito escolas. Foram ainda realizadas entrevistas com representantes dos serviços públicos de educação e saúde, das câmaras municipais com competência direta sobre a gestão das refeições das escolas selecionadas do $1 .{ }^{\circ}$ ciclo, com funcionários e membros da direção das escolas, bem como com funcionários das empresas de catering. As dimensões de análise cobriram as opiniões sobre os hábitos alimentares das crianças e eventuais mudanças com a entrada em vigor de iniciativas de promoção de alimentação saudável; os efeitos da crise económica na organização da alimentação escolar; as prioridades presentes e futuras no que respeita à qualidade alimentar nas escolas; os constrangimentos e limites à ação para a melhoria da alimentação escolar; as iniciativas e arranjos criativos nas escolas para contornar os efeitos das restrições orçamentais do Estado. Todo o material qualitativo recolhido foi transcrito e sujeito a análise de conteúdo através do software NVivo 10.

No próximo ponto analisam-se diferentes arranjos criativos alocados na rede de provisão estatal, bem como nas que emergem de parcerias entre esta e outras redes, sobretudo a comunitária e a doméstica. Esta análise não pretende apresentar os resultados empíricos em si, mas antes utilizar exemplos dos dados recolhidos para ilustrar os vários arranjos criativos emergentes.

\section{Criatividade descentralizada na rede de provisão estatal: flexibilização e aproveitamento dos recursos institucionais}

No conjunto das entrevistas realizadas a atores-chave do sistema de refeições escolares nas três regiões do país em estudo, encontram-se relatos sobre o aumento do número de famílias que aderem aos serviços prestados nos refeitórios escolares para fazer face à redução do seu poder económico.

“(...) Não sei se é devido à troika nem se não, o que se nota agora é que há mais encarregados de educação a solicitar alteração de escalão, independentemente de a Segurança Social lhes atribuir ou não essa alteração... (...) Eles alegam dificuldades económicas e financeiras." (Responsável dos serviços de ação social escolar, Norte, Fevereiro 2013.)

18 Algumas regiões têm tido dificuldades em assegurar o pagamento das refeições gratuitas dos alunos com apoio da Ação Social Escolar aos fornecedores, devido a atrasos nas transferências de verbas por parte dos órgãos centrais do Estado. Perante o recurso crescente às redes estatais e à fragilidade da sua resposta no atual contexto, verifica-se que algumas escolas e autarquias locais têm desenvolvido arranjos criativos para remediar problemas. Por exemplo, o alargamento do período de funcionamento 
dos refeitórios durante as férias escolares de modo a garantir o acesso das crianças mais carenciadas a, pelo menos, uma refeição quente diária. Contudo, a autonomia das autarquias e dos agentes do sistema educativo é condicionada com base nos recursos de que dispõem. $O$ relato de duas funcionárias de uma das câmaras municipais (doravante, Câmara Municipal A) mostra que a resposta que os serviços têm procurado dar não representa uma solução sistemática e centralizada, mas antes o resultado da solidariedade e da criatividade dos profissionais envolvidos e de acordo com a autonomia que detêm.

"Nas interrupções letivas e nas férias escolares, desde que tenhamos um mínimo de sete, oito crianças, inscritas na componente de apoio à família, mantemos o refeitório a funcionar nas mesmas condições que durante o ano letivo. Isto não tem comparticipação estatal.” (Câmara Municipal A, Novembro 2011.)

19 Neste caso, o desenvolvimento de soluções socialmente justas parte da iniciativa local e da sua capacidade de intervenção cívica, tal como defendido por Sulkunen (2009). Porém, a descentralização da resposta social e a transferência dessa responsabilidade para os agentes institucionais locais (autarquias e escolas) pode provocar assimetrias territoriais e sociais, dependendo da capacidade de resposta destes agentes locais. Para ilustrar esta possibilidade, veja-se uma notícia da imprensa escrita que dá conta de uma situação em que o volume das dívidas acumuladas pelos encarregados de educação referentes ao pagamento da alimentação escolar conduziu a direção do agrupamento a fazer um ultimato aos pais que estavam em dívida. 0 não pagamento desta dívida resultaria na proibição dos respetivos educandos de frequentarem o refeitório, negando assim o acesso a um serviço público ${ }^{3}$.

Apesar disto, é inegável a existência de arranjos criativos que emergem da rede de provisão estatal, colmatando muitas vezes as necessidades imediatas dos mais carenciados. Os funcionários da mesma Câmara Municipal apontaram que, quando são referenciadas situações de carência alimentar e/ou de novas dificuldades económicas, a gestão do apoio municipal e da ação social escolar na alimentação tende a ser flexibilizada com o propósito de resolver situações pontuais ou imprevistas:

"Nós temos, de facto, um sistema muito facilitador em relação às questões da carência (...). Ou seja, o mecanismo está muito agilizado para as famílias que tenham qualquer percalço poderem passar a escalões com comparticipações mais diminuídas ou a custo zero, como é o escalão A." (Câmara Municipal A, Novembro 2011.)

O mesmo tipo de flexibilização e aproveitamento dos recursos institucionais também se verifica nas escolas, como se confirma no excerto seguinte:

"Há casos em que os encarregados de educação vêm solicitar essa alteração de escalão. Nós alegamos sempre '- Ah, mas a Segurança Social ainda não alterou, portanto, nós temos que ponderar isto muito bem'. Depois, eles fazem o pedido, nós analisamos e os dois tentamos reunir informação para ver se se justifica, ou não, essa alteração de escalão. Quando o processo está concluído, remetemos à direção e normalmente é o conselho administrativo da escola que, mediante os nossos pareceres, diz sim ou não." (Responsável dos serviços de ação social escolar, Norte, Fevereiro 2013.)

Esta flexibilização decorre de uma maior ou menor coordenação com as direções e os serviços, da sensibilidade da escola para este tipo de problemas, e da sinalização de casos problemáticos através da vigilância nos refeitórios feita por professores e funcionários: 
"Nunca deixamos as crianças sem almoçar. Mesmo quando há crianças que se esquecem de marcar a senha e o programa não deixa tentamos sempre [deixá-los almoçar], independentemente de eles não terem o processo completo [em ordem]." (Responsável dos serviços de ação social escolar da escola EB 2,3, Norte, Fevereiro 2013.)

“A gente aqui sabe que há muita (crise), porque nós conhecemos as crianças todas daqui, não é? Basta nós morarmos aqui nas redondezas para conhecer. Nós sabemos que as crianças [...] têm dificuldades, os pais não lhes... pronto, não os tratam como deve ser. (...) Mas dizer assim, que eles nos digam, ou...tenho fome por isto...não (...) se a gente perceber que eles [as crianças] querem, somos capazes de... olha, fazer uma sandes..."' (Pessoal de cozinha, Escola EB1, Lisboa Suburbano, Maio 2012.)

Estes "arranjos" criativos são assim provisórios, não sendo pensados como soluções estratégicas definitivas para os problemas que a escola ou a autarquia enfrentam no seu dia-a-dia. São processos inacabados que se podem rearranjar e transformar consoante as imprevisibilidades quotidianas.

Mas apesar de ser possível implementar arranjos criativos dentro dos limites da ação institucional "jogando" com os recursos disponíveis, observam-se situações em que as normas que regulam o sistema de refeições escolares (e.g. higiene, segurança alimentar) constrangem a autonomia das escolas para resolver problemas de carência alimentar. Um dos casos que ilustra bem este constrangimento é a proibição do uso das sobras das refeições. Atualmente, as empresas fornecedoras de serviços não permitem que as sobras sejam aproveitadas devido aos critérios apertados de higiene e segurança alimentares que devem ser cumpridos no fornecimento de refeições ${ }^{4}$.

"Não há um dia em que possa dizer, hoje a maioria [dos alunos] comeu tudo. [0 desperdício] vai para o meio dos pratos, vai logo para o lixo. (...) Os restos também, por exemplo, às vezes dos miúdos que faltam [....]. Isso vai para o lixo." (Pessoal de cozinha, Escola EB1, Lisboa Suburbano, Maio 2012.)

Apesar das resistências oferecidas relativamente ao aproveitamento das sobras, algumas escolas disponibilizam, ao lanche ou ao fim do dia, o pão que sobrou do almoço e/ou do lanche de modo a remediar situações de carência alimentar existentes em casa.

“(...) existe alguma flexibilidade por parte das escolas, porque algumas convivem com realidades muito diferentes, e há uma preocupação da escola. À saída muitos podem levar o lanche ou outra coisa que possa ter sobrado. Muitos já estão identificados que vão chegar a casa e não têm nada para comer. Isto é uma situação que varia muito em função do local e da sensibilidade da escola." (Entrevista a uma representante de um serviço público de saúde, Madeira, Março 2012.)

Reforça-se aqui a importância das redes de provisão estatais para garantir o acesso a uma alimentação regular e adequada, particularmente nos casos em que as redes de provisão doméstica são insuficientes. Além disso, também se identifica um caso em que foi estabelecida uma parceria entre a escola e a família para o fornecimento do lanche à criança, o qual não era antes providenciado. Uma vez que era frequente sobrar pão do almoço, pediu-se aos pais para enviarem para a escola o recheio do pão (e.g. doce), maximizando-se assim o aproveitamento das sobras e a redução dos custos dos lanches para as famílias. Este exemplo ilustra a contratualização entre as duas redes de provisão: a estatal e a doméstica. Através destas ilustrações empíricas, verifica-se que a crise económica está a ter um efeito restritivo no poder de compra das famílias. Isso representa dificuldades no acesso aos circuitos de mercado e, em alguns casos, na organização da provisão alimentar doméstica. Perante essas dificuldades, as famílias recorrem mais às redes de provisão 
estatais como, por exemplo, as refeições escolares. As estruturas governamentais que suportam as redes de provisão estatais (e.g. fornecimento de refeições escolares) também foram afetadas pela conjuntura económica atual, não obstante, desenvolveu-se um conjunto de iniciativas locais para enfrentar essas fragilidades. Ao não representarem uma solução universal, coadunam-se com a visão de que a satisfação do bem-estar coletivo depende cada vez mais da autonomia, da criatividade e da cidadania dos indivíduos, aplicada nas esferas pessoal, pública e profissional. As escolas, as autarquias e as famílias, quando limitadas pelos recursos que detêm, são muitas vezes obrigadas a contratualizar entre si soluções que emergem do confronto local com os desafios. Desta forma, surgem práticas inovadoras que interferem ativamente na organização dos mecanismos institucionais que garantem os direitos sociais.

\section{Criatividade centralizada na rede de provisão estatal: parcerias entre o Estado e a comunidade}

Na secção anterior analisaram-se os arranjos criativos que decorriam da capacidade de autonomia dos agentes institucionais descentralizados para garantir o acesso das crianças à alimentação escolar. Nesta seç̧ão, apresenta-se uma iniciativa identificada no decorrer do trabalho de campo, a qual foi desenvolvida recentemente. Esta iniciativa, materializada num programa alimentar, tem como objetivo atenuar as carências de crianças comprovadamente necessitadas através do fornecimento do pequeno-almoço na escola.

Em Novembro de 2012, o Ministério da Educação e Ciência implementou o Programa Escolar de Reforço Alimentar (PERA) com o objetivo de disponibilizar a primeira refeição do dia às crianças mais necessitadas e de sensibilizar as famílias para a importância do pequeno-almoço. Este projeto resulta de um conjunto de parcerias estabelecidas entre o Ministério da Educação e Ciência e várias entidades (e.g. Associação Nacional de Municípios Portugueses, sector empresarial, escolas, redes locais de ação social, Banco Alimentar contra a Fome ou outras IPSS) e não representa uma solução universal mas sim um apoio social à promoção da igualdade (MEC, 2012). Além disso, neste programa, o fornecimento do pequeno-almoço gratuito é considerado apenas uma fase transitória, uma vez que o objetivo é sinalizar esses grupos da população e desenvolver uma intervenção que passa por disponibilizar em casa e na escola os alimentos provenientes das parcerias estabelecidas. De acordo com o documento publicado sobre o PERA (MEC, 2012), em 364 escolas, aproximadamente 12 000 alunos tomavam o pequeno-almoço na escola e quase $50 \%$ estavam cobertos por este programa em 2012.

Contrariamente ao caso anterior, em que os arranjos criativos surgiam ao nível da iniciativa local e descentralizada (embora dentro das redes de provisão estatal), neste caso concreto o Estado central inovou por meio de arranjos criativos para atenuar problemas de carência alimentar. Não obstante, este programa sustenta-se no modelo contratualista apontado por Sulkunen (2009), e como tal transfere responsabilidades sociais, que antes eram providenciadas pelo Estado, para um conjunto de entidades que atuam em diferentes redes de provisão alimentar (empresas, bancos alimentares, IPSS, autoridades locais, etc.).

31 No entanto, segundo as orientações constitutivas do PERA, este programa não pode substituir iniciativas similares que já tenham sido desenvolvidas no âmbito da 
autonomia local das escolas e das autarquias (MEC, 2012). Como se pode verificar nos excertos seguintes, para as escolas que estão inseridas nas regiões em estudo e que tiveram conhecimento do PERA, esta iniciativa não foi muito útil. Isto porque a maioria já tinha em curso arranjos criativos locais, como é o caso do fornecimento do suplemento alimentar.

"Já ouvimos falar [do PERA] mas penso que, na minha opinião pessoal, nós já o temos... Quando a pessoa vir que aquele menino realmente precisa [do suplemento alimentar], faz o pedido e, a partir daí, desencadeia-se todo o processo." (Responsável dos serviços de ação social escolar da escola EB 2, 3, Norte, Fevereiro 2013.)

“Os agrupamentos, as direções dos agrupamentos, os diretores, pelo menos há já três, quatro anos, que fazem reforços alimentares a alunos que chegam lá e tomam o pequeno-almoço pela manhã, é-lhes dado um reforço a meio da manhã e a meio da tarde outro reforço, para além do almoço que também passa a ser totalmente gratuito." (Representante da Câmara Municipal C, Fevereiro 2013.)

Apesar de o Estado ter desenvolvido um programa central de apoio social, a maioria das escolas em análise já interveio para atenuar as carências alimentares das crianças. Além disso, a concretização dos objetivos deste programa reside no aproveitamento do capital social do Estado (no seu papel de facilitador) para fazer a ponte entre as famílias carenciadas e as redes de provisão comunitárias. Neste caso concreto, nota-se assim uma mudança de papel do Estado: de provedor para facilitador. Deste modo, prevalece a visão contratualista do bem-estar social tal como explicitado por Sulkunen (2009) e Somers (2008). Isto é, numa situação de desmantelamento do Estado Social, a proteção dos cidadãos é transferida para as famílias, a sociedade civil e o mercado, deixando de estar assegurada exclusivamente pelas redes de provisão estatais. Porém, a presença do Estado continua a ser requerida, mesmo que reduzido a um papel de facilitador acionado por meio do seu capital social.

\section{Comentários finais}

Nesta análise verifica-se que, em Portugal, o agravamento da situação económica das famílias está a fazer que o seu consumo alimentar seja cada vez mais dependente, tanto das redes de provisão estatal (acesso à alimentação nas escolas públicas), quanto das redes comunitárias que se formam como alternativa de acesso ao consumo alimentar (PERA).

Partindo dos debates de Sulkunen (2009) e Somers (2008) sobre o Estado Social, e utilizando a tipologia de redes de provisão de bens e serviços proposta por Harvey et al. (2001), identificaram-se alguns arranjos criativos levados a cabo em escolas selecionadas de três regiões do país para garantir a segurança alimentar das crianças. Nos exemplos empíricos analisados, ilustrámos a criatividade (des)centralizada dentro da rede de provisão estatal. A análise de iniciativas criativas permitiu observar diferentes formas da sua expressão nas redes de provisão estatal. Por um lado, verificou-se a existência de arranjos criativos descentralizados (ao nível local da autarquia e da escola pública) que permitiram uma flexibilização e o aproveitamento dos recursos institucionais. Por outro lado, identificaram-se arranjos criativos centralizados que foram consolidados através de parcerias entre o Estado central e um conjunto de entidades que atuam em diferentes redes de provisão alimentar (empresas, bancos alimentares, IPSS, autoridades locais, etc.). Como se pôde ver através do PERA, a 
privatização e contratualização dos serviços do Estado colocou o acesso a alguns bens e serviços sob uma maior dependência das redes comunitárias. Nota-se aqui uma mudança de papel do Estado - de provedor a facilitador -, utilizando o seu capital social para fazer parcerias entre os indivíduos, as famílias, a sociedade civil e o mercado.

Conclui-se que, apesar da atual fragilização do Estado Social, as redes de provisão estatais continuam a ser centrais para providenciar bens e serviços, tais como a alimentação escolar, recorrendo a arranjos criativos que tentam colmatar os efeitos da crise económica e das políticas de teor neoliberal. Perante isto, há um conjunto de questões pertinentes a explorar. Até que ponto é que as dinâmicas empiricamente ilustradas - tanto nas refeições escolares como no PERA - corroboram o argumento em torno do desmantelamento do Estado Social (Sulkunen, 2009; Somers, 2008)? Isto porque, apesar do seu desmantelamento, o Estado continua a ser requisitado para garantir a segurança alimentar na escola pública, ainda que tendo, por vezes, de reconfigurar o seu papel de principal provedor para facilitador. Que outros exemplos se podem encontrar além da alimentação escolar de arranjos criativos, sempre provisórios e em aberto, para colmatar as fragilidades do Estado Social? Será que a análise mais aprofundada destes arranjos criativos noutras áreas de atuação do Estado pode contribuir para desenvolvimentos teóricos sobre as instituições (estatais ou outras) e a criatividade na austeridade? Estas são algumas pistas para futuras investigações e reflexões teórico-empíricas.

Este artigo foi apresentado originalmente ao VII Congresso Português de Sociologia (19-22 Junho 2012). Agradecemos à audiência os comentários e críticas recebidos que ajudaram a reformular substancialmente o presente texto. Agradecemos igualmente os comentários construtivos de dois revisores anónimos para a melhoria deste artigo. Este trabalho beneficia de financiamento da Fundação para a Ciência e a Tecnologia [PTDC/CS-SOC/111214/2009].

\section{BIBLIOGRAFIA}

COMISSÃO EUROPEIA (2012), The distributional effects of austerity measures: A comparison of six EU countries, Report, Social Situation Observatory.

COSTA, A. (2012), “Desigualdades Globais”, in Sociologia, Problemas e Práticas, 68, pp. 9-32.

CRUZ, I. (2011), “Práticas de consumo: o que faz a diferença?”, Sociologia Online, 4, pp. 7-25.

DEVAULT, M. (1991), Feeding the family: the social organization of caring as gendered work, Chicago, University of Chicago Press.

DOWLER, E. e D. O'Connor (2012), "Rights-based approaches to addressing food poverty and food insecurity in Ireland and UK”, Social Science \& Medicine, 74(1), pp. 44-51.

EVANS, B. (2010), “Anticipating fatness: childhood, affect and the pre-emptive "war on obesity", Transactions of the Institute of British Geographers, 35, pp. 21-38.

HARVEY, M.; A. McMeekin, et al. (2001), "Between Demand and Consumption: a framework for research", CRIC Discussion Paper n. 40, Manchester, University of Manchester. 
LAMBIE, H. (2011), “The Trussell Trust Foodbank Network: Exploring the Growth of Foodbanks Across the UK", Final Report, Coventry, Coventry University.

LAMBIE-MUMFORD, H. e D. Jarvis (2012), “The role of faith-based organisations in the Big Society: opportunities and chalenges", Policy Studies, 33(1), pp. 37-41.

MEC (2012), Programa Escolar de Reforço Alimentar, Lisboa, Ministério da Educação e Ciência.

MORGAN, K. (2011), “The coming crisis of school food: from sustainability to austerity?", Welsh Economic Review, 22, pp. 32-35.

SANTOS, M. (2012), Quando Portugal bateu à porta da sociedade de consumo, Notas para a intervenção no "Seminário 30 anos da primeira Lei de Defesa do Consumidor", disponível em http:// movimento.vidasalternativas.eu/index.php/temas-beja-santos/4374-uma-sociedade-deconsumo-a-portuguesa-por-mario-beja-santos.html, acedido pela última vez a 20 de Outubro de 2012.

SOMERS, M. (2008), Genealogies of Citizenship: Markets, Statelessness and the Right to Have Rights, Cambridge, Cambridge Cultural Social Studies.

SULKUNEN, P. (2009), The Saturated Society: governing risk and lifestyles in consumer culture, Londres, Sage.

TRUNINGER, M.; J. Teixeira, et al. (2012), A evolução do sistema de refeições escolares em Portugal (1933-2012): 1.ํㅡㄹ relatório de pesquisa, Lisboa, Instituto de Ciências Sociais da Universidade de Lisboa.

UNICEF (2012), Measuring child poverty: New league tables of child poverty in the world's rich countries, Report, Florença, Innocenti Research Centre.

WARDE, A. (1992), "Notes on the relationship between production and consumption". In R. Burrows e C. Marsh (eds.), Consumption and Class: divisions and change, Londres, Macmillan, pp. 15-31.

\section{NOTAS}

1. Neste artigo, a expressão "arranjos criativos" reporta-se às várias iniciativas de reorganização das instituições de forma a resolver problemas com que lidam no seu quotidiano. Estes arranjos nunca são definitivos, sendo situações provisórias e sempre em aberto, as quais exigem flexibilidade e criatividade constantes dos seus agentes.

2. Mais concretamente, referimo-nos ao projeto Entre a Escola e Família: conhecimentos e práticas alimentares das crianças em idade escolar [PTDC/CS-SOC/11121/2009], financiado pela Fundação para a Ciência e a Tecnologia, que tem por objetivo analisar as várias formas de organização da alimentação escolar em Portugal, identificar diversas iniciativas de alimentação saudável e as principais prioridades das políticas públicas neste âmbito, nas escolas do Ensino Básico.

3. "Diretora nega que criança tenha ficado sem comer", notícia publicada no Expresso a 17 de Outubro de 2012.

4. Apesar de a maioria das empresas de catering afirmar que não é permitido o aproveitamento de sobras, identificou-se uma associação contra o desperdício alimentar (Dariacordar) que desenvolveu, em conjunto com a Autoridade de Segurança Alimentar e Económica (ASAE), um manual de boas práticas. Este manual possibilita a recolha, o transporte e a distribuição de refeições aproveitadas a partir das sobras alimentares de restaurantes, grandes superfícies e outros fornecedores. O cumprimento destas orientações possibilita que as sobras possam ser legalmente distribuídas. 


\section{RESUMOS}

Em Portugal, a crise económica tem afetado vários grupos da população, em especial os mais vulneráveis, e obrigado a reconfigurar os serviços sociais prestados pelo Estado. Com base num estudo sobre alimentação escolar, examina-se o modo através do qual a retração do Estado Social está a interferir na sustentabilidade das redes de provisão alimentar na escola pública e, concomitantemente, a reconfigurar a sua eficácia através de 'arranjos' criativos das autarquias, da comunidade escolar e de parcerias com outras redes de provisão. O caso das refeições escolares públicas oferece uma pertinente entrada para examinar as atuais tensões e reconfigurações de "arranjos" institucionais criativos das várias redes de provisão alimentar em situação de crise económica. Conclui-se que, apesar da atual fragilização do Estado Social, o Estado - tanto na sua vertente mais centralizadora como descentralizadora - continua a manter uma posição central como facilitador do acesso à alimentação escolar através do recurso a arranjos institucionais criativos, os quais tentam colmatar, na medida do possível, os efeitos da crise económica e das políticas de teor neoliberal.

In Portugal, the economic crisis has affected various groups of the population, especially the most vulnerable, and forced to reconfigure social services provided by the state. Based on a case study of public school meals, this article examines the way in which the decline of the welfare state is interfering in the sustainability of school's food provisioning systems and, concomitantly, reconfiguring its effectiveness through the creative capacity of local authorities, school community and partnerships with other modes of provision. The case of school meals provides a gateway to examine the current tensions and reconfigurations moulded through creative institutional arrangements of the various food provisioning systems in times of economic contraction. It is concluded that despite the current weakening of the welfare state, the state both in its more centralized and decentralized form - continues to hold a central position as a facilitator of access to school meals through institutional creative arrangements, which seek to overcome the effects of the economic crisis and neoliberal policies.

welfare state, school meals, creativity, economic crisis

\section{ÍNDICE}

Palavras-chave: estado social, alimentação escolar, criatividade e crise económica

\section{AUTORES}

\section{MÓNICA TRUNINGER}

Doutora em Sociologia pela Universidade de Manchester, Reino Unido. Investigadora Auxiliar do Instituto de Ciências Sociais da Universidade de Lisboa, Portugal (monica.truninger@ics.ul.pt)

\section{JOSÉ TEIXEIRA}

Mestrando em Comunicação, Cultura e Tecnologias da Informação do ISCTE-IUL (Lisboa, Portugal). Investigador assistente do Instituto de Ciências Sociais da Universidade de Lisboa, Portugal (jose.teixeira@ics.ul.pt) 


\section{ANA HORTA}

Doutora em Sociologia da Comunicação, Cultura, Educação pelo ISCTE (Lisboa, Portugal). Investigadora Pós-doc no Instituto de Ciências Sociais da Universidade de Lisboa (ana.horta@ics.ul.pt)

\section{SÍLVIA ALEXANDRE}

Doutora em Gestão pelo ISCTE (Lisboa, Portugal). Investigadora Pós-Doc no SOCIUS, Instituto Superior de Economia e Gestão (scpalexandre@gmail.com)

\section{VANDA A. DA SILVA}

Doutora em Ciências Sociais pela UNICAMP, SP, Brasil. Investigadora colaboradora no CRIA/ ISCTE-IUL (Lisboa, Portugal), CERES/UNICAMP (Campinas, Brasil)

(vandaaparecida.silva@gmail.com) 